\title{
Can Prenatal N-3 Fatty Acid Deficiency Be Completely Reversed after Birth? Effects on Retinal and Brain Biochemistry and Visual Function in Rhesus Monkeys
}

\author{
GREGORY J. ANDERSON, MARTHA NEURINGER, DON S. LIN, AND WILLIAM E. CONNOR \\ Division of Endocrinology, Diabetes and Clinical Nutrition, Department of Medicine [G.A., M.N., D.S.L., \\ W.E.C.], Division of Neuroscience [M.N.], Oregon National Primate Research Center, Department of \\ Ophthalmology [M.N.], Oregon Health and Science University, Portland, Oregon, 97239
}

\begin{abstract}
Our previous studies of rhesus monkeys showed that combined prenatal and postnatal n-3 fatty acid deficiency resulted in reduced visual acuity, abnormal retinal function, and low retina and brain docosahexaenoic acid content. We now report effects of n-3 fatty acid deficiency during intrauterine development only. Rhesus infants, born to mothers fed an n-3 fatty acid deficient diet throughout pregnancy, were repleted with a diet high in alpha-linolenic acid from birth to 3 y. Fatty acid composition was determined for plasma and erythrocytes at several time points, for prefrontal cerebral cortex biopsies at 15 , 30,45 , and $60 \mathrm{wk}$, and for cerebral cortex and retina at $3 \mathrm{y}$. Visual acuity was determined behaviorally at 4, 8, and 12 postnatal weeks, and the electroretinogram was recorded at 3-4 mo. Total n-3 fatty acids were reduced by $70-90 \%$ in plasma, erythrocytes, and tissues at birth but recovered to control values within $4 \mathrm{wk}$ in plasma, $8 \mathrm{wk}$ in erythrocytes, and $15 \mathrm{wk}$ in
\end{abstract}

\section{ABSTRACT}

cerebral cortex. At $3 \mathrm{y}$, fatty acid composition was normal in brain phospholipids, but in the retina DHA recovery was incomplete (84\% of controls). Visual acuity thresholds did not differ from those of control infants from mothers fed a high linolenic acid diet. However, the repleted group had lower amplitudes of cone and rod ERG a-waves. These data suggest that restriction of n-3 fatty acid intake during the prenatal period may have longterm effects on retinal fatty acid composition and function. (Pediatr Res 58: 865-872, 2005)
Abbreviations
DHA, docosahexaenoic acid, 22:6(n-3)
ERG, electroretinogram
PE, phosphatidylethanolamine
PS, phosphatidylserine

The long-chain n-3 fatty acid, DHA [22:6(n-3)], is especially rich in the membrane phospholipids of the brain, retina, and spermatozoa (1). Tissue DHA may be obtained directly from the diet or biosynthesized from alpha-linolenic acid [18:3(n3)]. Studies in rodents, monkeys, and human infants have demonstrated abnormalities in retinal function and visual capacity when the dietary supply of $n-3$ fatty acids is limited during development (2-9).

In a nonhuman primate model, we fed diets very low in alpha-linolenic acid to female monkeys during pregnancy and to their newborns for $2 \mathrm{y}$ to induce combined prenatal and postnatal n-3 fatty acid deficiency. The functional consequences included slowed visual acuity development, abnormal-

Received December 7, 2004; accepted March 31, 2005.

Correspondence: William E. Connor, M.D., Department of Medicine, L465 Oregon Health and Science University, Portland, OR 97239-3098; e-mail: connorw@ohsu.edu. This work was supported by National Institutes of Health grants DK29930, RR00163, RR00334, and DK40935, and a grant from The Foundation Fighting Blindness.

DOI: $10.1203 / 01 . p d r .0000182188 .31596 .5 a$ ities of the ERG, and increased fluid intake $(5,6,10)$, accompanied by substantial changes in fatty acid composition and in the phospholipid molecular species of the retina and cerebral cortex $(11,12)$. In particular, levels of DHA were reduced by $80-85 \%$ in comparison to mothers and infants fed relatively high levels of alpha-linolenic acid. DHA was largely replaced by an $n-6$ fatty acid, 22:5(n-6), such that the total proportion of polyunsaturated fatty acids in the retina and brain was maintained.

In the present study, we examined the importance of dietary n-3 fatty acids in nonhuman primates during intrauterine life. We previously demonstrated that an $n-3$ fatty acid-deficient maternal diet during pregnancy (prenatal deficiency) would substantially reduce levels of n-3 fatty acids in the blood and tissues of newborn infant monkeys $(5,6)$. Here we examined whether feeding an infant formula high in alpha-linolenic acid from birth would correct the biochemical n-3 fatty acid deficiency caused by deprivation of the mother during pregnancy, and whether the prenatal n-3 fatty acid deprivation resulted in 
functional consequences similar to those seen in combined prenatal and postnatal deficiency.

\section{METHODS}

All procedures were reviewed by the Institutional Animal Care and Use Committee of the Oregon National Primate Research Center and were conducted in accordance with approved methods and guidelines of the U.S. Department of Agriculture, the National Institutes of Health, and the Federation of American Societies for Experimental Biology.

Subjects and diets. Four female rhesus monkeys (Macaca mulatta) were fed an n-3 fatty acid deficient semipurified diet and five were fed a control diet for at least 2 mo before conception and throughout pregnancy. The deficient diet contained high-linoleic safflower oil $(<0.3 \%$ of total fatty acids as alpha-linolenic acid, n-6:n-3 fatty acid ratio 250:1). The control diet was identical except for the source of fat, which was soybean oil (7.7\% of total fatty acids as alpha-linolenic acid, n-6:n-3 fatty acid ratio 7:1). Because linoleic acid [18:2(n-6)] and alpha-linolenic acid compete for delta-6 desaturase in the biosynthetic pathway for long-chain polyunsaturated fatty acids, the high dietary n-6 to n-3 ratio in the deficient diet tends to accentuate further the n-3 fatty acid deficiency caused by feeding low levels of alpha-linolenic acid. From birth until completion of the study at $3 \mathrm{y}$ of age, the offspring of both groups of mothers, four prenatally deficient and five control infants, were fed soybean oil control diets with the same fatty acid composition as the maternal control diet. A liquid infant formula soybean oil diet (30\% kcal as fat) was fed until 18 mo of age, followed by the same solid diet fed to control mothers $(13.4 \%$ of kcal as fat). The fatty acid compositions of the diets were monitored monthly. Typical compositions of the safflower oil and soybean oil diets are shown in Table 1, whereas other details of diet composition have been described previously $(5,6)$.

Erythrocyte fatty acid data are included for additional concurrent control infants (two at $24 \mathrm{wk}$ and four at $36 \mathrm{wk}$ ) and for one additional prenatally deficient concurrent infant at birth. For visual acuity, data are included for an additional seven control infants. All of these animals received identical diets and were reared, housed, and tested under the same conditions as the groups described above. Also, in some cases we include previously published data from animals reared under identical conditions. Specifically, control and deficient infants at birth, and control animals at 2-3 y, were not killed concurrently for cerebral cortex and retinal fatty acid analyses, but rather data from Ref. 6 were used for comparison. Similarly, plasma data were not available from concurrent control infants at the time of birth but were taken from Ref. 5. In the case of the prenatally deficient group, only three of the four animals were killed at $3 \mathrm{y}$ of age. For each outcome, the number of subjects is given in the corresponding subsection below and in the tables and figure legends.

Visual acuity. Visual acuity thresholds were determined with the preferential looking method (13) at 4, 8 and $12 \mathrm{wk}$ of age as previously described (5). This method uses infants' inherent tendency to fixate high-contrast visual stimuli to estimate the smallest stripes that they can detect. Infants were held in an experimenter's lap $35 \mathrm{~cm}$ from a stimulus display while an observer

Table 1. Fatty acid composition of the experimental diets (percentage of total fatty acids)

\begin{tabular}{|c|c|c|}
\hline Fatty Acid & $\begin{array}{l}\mathrm{n}-3 \text { fatty acid } \\
\text { deficient diet } \\
\text { (safflower oil) }\end{array}$ & $\begin{array}{c}\text { Control diet } \\
\text { (n-3 fatty acid adequate) } \\
\text { (soybean oil)* }\end{array}$ \\
\hline $16: 0$ & 7.1 & 10.7 \\
\hline $18: 0$ & 2.5 & 4.2 \\
\hline Saturated & 10.0 & 16.4 \\
\hline $18: 1(n-9)$ & 13.3 & 23.7 \\
\hline Monounsaturated & 13.8 & 24.2 \\
\hline $18: 2(n-6)$ & 76.0 & 53.1 \\
\hline $20: 4(n-6)$ & - & - \\
\hline Total $(n-6)$ & 76.5 & 53.4 \\
\hline $18: 3(n-3)$ & 0.3 & 7.7 \\
\hline $20: 5(n-3)$ & - & - \\
\hline $22: 6(n-3)$ & - & - \\
\hline Total (n-3) & 0.3 & 7.7 \\
\hline$n-6 / n-3$ & 255.0 & 7.0 \\
\hline
\end{tabular}

* Fed at birth to both the control infants and the prenatally $\mathrm{n}-3$ fatty acid-deficient infants. watched their fixations and eye movements through a central peephole. The display seen by the infant consisted of a gray panel with two openings for the stimuli, which consisted of one high-contrast horizontal square-wave grating mounted on an $11 \times 11 \mathrm{~cm}$ card and an even gray card of the same space-averaged luminance. The right-left position of the striped card was randomized from trial to trial. At least 20 trials were presented for each of 5 or 6 spatial frequencies (stripe sizes) that bracketed the expected acuity threshold for a given age, with the different sizes presented in pseudorandom order. The observer, without knowing the position or size of the stripes, judged whether the infant looked to the right or left, and looks to the striped card were scored as correct. The percentage correct was plotted as a function of stripe size, and the acuity threshold was determined from this function as the highest frequency corresponding to $75 \%$ correct. Testing was completed over 2-4 d, with the final session on the day the infant reached 4,8 , or $12 \mathrm{wk}$ of age, \pm 2 d. Data are presented for 4 prenatally deficient infants and 12 control infants [5 tested during the same time period and 7 incorporated from earlier studies (6) to increase the sample size]. No difference in acuity thresholds was found between the earlier and concurrent control cohorts.

ERG. Full-field ERG were recorded at 3-4 mo of age from four prenatally deficient infants and five concurrent control infants. Pupils were maximally dilated with $1 \%$ cyclopentolate and $10 \%$ phenylephrine, the cornea was anesthetized with $1 \%$ proparacaine, and the animals were then anesthetized with i.v. thiamylal $(25 \mathrm{mg} / \mathrm{kg}$ initial dose, supplemented as needed). Recordings were obtained from the right eye with custom Burian-Allen bipolar corneal contact lens electrodes designed for infant monkeys (Hansen Laboratory, Iowa City, IA); a ground electrode was placed on the scalp. Full-field stimulus flashes (10 $\mu$ s duration) produced by a Grass PS-22 photostimulator were diffused within a spherical dome. Flash intensities were presented in 0.6 $\log$ unit intensity steps over a $4.2 \mathrm{log}$ unit range. The ERG signal was amplified at gain 10,000, passband $1-1000 \mathrm{~Hz}$ for light-adapted responses and gain 5000, passband $0.3-1000 \mathrm{~Hz}$ for dark-adapted responses.

Isolated responses were obtained from the cone and rod systems, which are responsible for day and night vision, respectively. Light-adapted responses, predominantly of the cone system, were isolated using $30 \mathrm{~Hz}$ flicker or single white flashes superimposed on a steady adapting background (intensity 80 $\mathrm{cd}-\mathrm{sec} / \mathrm{m}^{2}$ ), both conditions that suppress the response of the rod system. For both types of cone system response, 100 waveforms were averaged at each stimulus intensity. Rod system-dominated responses were recorded after 30 min of dark adaptation. An ascending series of white flashes was presented at intensities from threshold to b-wave saturation, and 10-20 responses were averaged at each stimulus setting. After at least $60 \mathrm{~min}$ of dark-adaptation, the speed of postflash recovery of the ERG response was examined by presenting trains of b-wave saturating flashes $\left(1.6 \mathrm{~cd}-\mathrm{sec} / \mathrm{m}^{2}\right)$ at intervals from 0.5 to $30 \mathrm{~s}$.

For each stimulus condition, the amplitudes and implicit times (latencies to the peak) of the two major wave form components, the a-wave and b-wave, were determined. The earliest component, the a-wave, has a negative voltage with respect to the cornea and its leading edge reflects the hyperpolarization of the photoreceptors; its amplitude was measured from the preflash baseline to its lowest point. The later b-wave is cornea-positive and largely reflects activity of bipolar cells; its amplitude was measured, according to convention, from the negative a-wave peak, or from the preflash baseline if no clear a-wave was present. Postflash recovery was evaluated by expressing a-wave and b-wave amplitudes at the $0.5-10 \mathrm{~s}$ interflash intervals as a proportion of the maximal amplitude, which was measured at 20-30 s intervals that allowed complete recovery of b-wave amplitude between flashes.

Blood and tissue collection. Serial blood samples were collected in EDTA from prenatally deficient and from control infants at $0,4,8,24$, and 36 wk and at termination. The samples at birth consisted of cord blood obtained at the time of cesarean section, and at other ages samples were obtained by femoral venipuncture. Samples were not successfully collected from all infants at all time points. For erythrocyte analyses, the number of samples from prenatally deficient infants was five at birth, four at $4-36 \mathrm{wk}$, and three at termination. For control erythrocytes, the number of samples at each age were 3, 4, 4, 7, 9 , and 4, respectively; samples from two additional controls were included at 24 wk and four at $36 \mathrm{wk}$. Plasma data were only available at birth and at termination, and the plasma data shown for six control infants at birth were previously reported (5).

To evaluate the time course of brain repletion, biopsies of prefrontal cerebral cortex gray matter were obtained at 15-60 wk of age from the four prenatally $\mathrm{n}-3$ fatty acid-deficient monkeys. A neurosurgeon or veterinary surgeon carried out the biopsies under thiamylal anesthesia $(25 \mathrm{mg} / \mathrm{kg})$ using sterile procedures, as previously described (14). Small samples (15-30 mg) of prefrontal cortex gray matter were obtained through a small burrhole in the frontal bone. No behavioral or neurologic changes were noted after the biopsies. A total of three to four biopsies were obtained from each monkey, so that three to four samples were available for analysis at each time point. At $3 \mathrm{y}$, three of the monkeys were killed under deep pentobarbital anesthesia, and 
plasma, erythrocytes, prefrontal cerebral cortex gray matter, and neural retina were collected for analysis. For comparison, previously published data (6) are included for prefrontal cortex and retinal fatty acid composition from five soybean oil control monkeys at birth and from four soybean oil control monkeys at $2 \mathrm{y}$ of age. No cerebral cortex biopsies were obtained from control infants.

Analysis of fatty acid composition. The methods of biochemical analysis were as reported previously (14). Plasma lipids were extracted by the procedure of Bligh and Dyer (15). Erythrocytes were washed three times with saline, and the lipids extracted by the procedure of Rose and Oklander (16). Cerebral cortex and retina samples were extracted by the method of Folch (17). Butylated hydroxytoluene $(5 \mathrm{mg} / 100 \mathrm{~mL})$ was added to all lipid extracts as an antioxidant.

The lipid extracts of plasma and erythrocytes were separated into four major lipid classes (phospholipids, FFA, triglycerides, and cholesteryl esters) by thin-layer chromatography on silica gel G plates $(500 \mu \mathrm{m}$, Analtech, Newark, DE) using hexane-chloroform-ethyl ether-acetic acid (80:10:10:1). PE and PS in the extracts of frontal cortex, and PE in the retinal extracts, were separated by a different thin-layer chromatography system, using precoated silica gel 60 plates (EM Science, Gibbstown, NJ) and methyl acetate:n-propanol:chloroform:methanol:0.25\% KCl (25:25:25:10:9). The fatty acids in each lipid class or phospholipid class were transmethylated with boron trifluoride-methanol (18). Methyl esters of fatty acids were analyzed by gas-liquid chromatography (14) on an instrument equipped with a hydrogen flame ionization detector (PerkinElmer Model 8500, Norwalk, CT) and a 30-meter SP-2330 fused silica capillary column (Supelco, Bellefonte, PA). Temperatures of the column, detector, and injection port were 195,250 , and $250^{\circ} \mathrm{C}$, respectively. Helium was used as the carrier gas at an inlet pressure of $80 \mathrm{psi}$ and a split ratio of 1:170. The retention time and area of each peak were measured by an HP-3390 integrator; no correction factors were applied to integrated peak areas. A mixture of fatty acid standards was run daily.

Statistics. Statistical evaluation of the effects of diet and time on tissue fatty acid composition was done by ANOVA (SigmaStat, Jandel Scientific, Costa Madre, CA), except as noted. Where data for a particular fatty acid failed tests of normality or equal variance, the ANOVA was performed on logtransformed data. Posthoc differences between individual means were tested by use of the appropriate $t$ statistic (19). The Bonferroni inequality $(12,20)$ was used to control the $\alpha$ level, so that the reported $p$ values represent an overall probability adjusted for multiple comparisons. For example, for a given outcome measure the exact $p$ values for each pairwise comparison were calculated; these $p$ values were then summed, starting from the lowest $p$ value to the highest. The summation was stopped when the next $p$ value would push the sum beyond 0.05 . Within a given table, the highest such summation of $p$ values for all of the outcome measures within a given logical grouping (e.g. PE fatty acids in Table 4) is given as the cutoff (which was never greater than 0.05 ). For a more detailed description of this procedure, see Ref. 12. For effects of diet on visual acuity, visual acuity thresholds in cycles per degree of visual angle were subjected to $\log$ base 2 transformation and analyzed using GLM (SigmaStat), which adjusted for three missing values. For ERG parameters, repeated measures ANOVA (group $\times$ intensity or interflash) were done using StatView (SAS Institute, Cary, NC), and Bonferroni-Dunn tests provided posthoc comparisons between groups at each intensity or interflash interval.

\section{RESULTS}

Fatty acid composition of plasma and erythrocytes. In prenatally n-3 fatty acid-deficient monkeys, low n-3 fatty acid levels were present at birth in blood and tissues. In plasma phospholipids (Table 2), DHA was reduced by $85 \%$ and total n-3 fatty acids by $86 \%$ relative to control neonates from mothers fed the soybean oil diet. The n-6 fatty acid 22:5(n-6), the classic indicator of tissue n-3 fatty acid deficiency, increased to compensate partially for the decrease in DHA. In addition, changes were seen in saturated fatty acids, including an increase in plasma palmitic acid (16:0). These findings were essentially the same as those previously reported for another group of prenatally n-3 deficient newborn infants (5). After repletion from birth with the high-alpha-linolenic acid control diet, plasma total n-3 fatty acids and 22:5(n-6) returned to normal within 4 wk of birth $[6.0 \pm 2.4 \%$ versus $6.1 \pm 1.2 \%$ (control), and $0.7 \pm 0.5 \%$ versus $0.9 \pm 0.6 \%$ (control), respectively; full composition data not shown]. After 3 y of n-3 fatty acid repletion, plasma n-3 and n- 6 fatty acids in the prenatally deficient monkeys did not differ from the levels in control monkeys.

Erythrocyte fatty acids responded to the maternal n-3 fatty acid deficient diet in a less dramatic fashion, with reductions at birth of $45 \%$ in DHA, $80 \%$ in $22: 5(n-3)$, and $51 \%$ in total n-3 fatty acids compared with controls (Fig. 1, Table 3). The depleted DHA was replaced by the long-chain n-6 fatty acids 22:4(n-6) and 22:5(n-6). By 8 wk of age, total n-3 fatty acids in erythrocytes generally had recovered to control levels (Fig. 1 ), and by 12 wk 22:5(n-6) matched control values (0.8 $0.4 \%$ versus $0.8 \pm 0.3)$. The drop in erythrocyte DHA shortly

Table 2. Fatty acid composition of plasma phospholipids from prenatally n-3 deficient monkeys at birth and after 2-3 y of repletion with a control diet (percentage of total fatty acids, mean \pm SD)

\begin{tabular}{|c|c|c|c|c|}
\hline Fatty acid & \multicolumn{2}{|c|}{ At birth } & \multicolumn{2}{|c|}{ At $2-3 y$} \\
\hline 18:0 & $15.6 \pm 0.4^{*}$ & $18.9 \pm 1.4$ & $16.6 \pm 2.4^{*}$ & $21.2 \pm 0.9 \dagger$ \\
\hline Total saturated & $47.1 \pm 3.0$ & $42.7 \pm 6.6$ & $35.8 \pm 4.0 \dagger$ & $39.3 \pm 0.9$ \\
\hline $18: 1$ & $9.0 \pm 0.9$ & $10.2 \pm 1.2$ & $7.8 \pm 0.3$ & $7.6 \pm 0.4 \dagger$ \\
\hline $20: 4(n-6)$ & $13.6 \pm 4.7$ & $13.2 \pm 3.3$ & $6.6 \pm 4.4 \dagger$ & $5.8 \pm 1.5 \dagger$ \\
\hline $22: 4(n-6)$ & $1.0 \pm 0.5$ & $0.7 \pm 0.2$ & $0.7 \pm 0.3$ & $0.4 \pm 0.1$ \\
\hline $22: 5(n-6)$ & $1.8 \pm 0.6^{*}$ & $0.7 \pm 0.2$ & $0.8 \pm 0.3 \dagger$ & $0.1 \pm 0.1$ \\
\hline Total $(n-6)$ & $40.3 \pm 4.5$ & $37.8 \pm 5.8$ & $49.4 \pm 0.4 \dagger$ & $47.6 \pm 0.3 \dagger$ \\
\hline $18: 3(n-3)$ & $0.1 \pm 0.2$ & $0.1 \pm 0.1$ & $1.1 \pm 0.7 \dagger$ & $0.4 \pm 0.1$ \\
\hline $22: 5(n-3)$ & $0.1 \pm 0.1^{*}$ & $0.9 \pm 0.2$ & $0.8 \pm 0.4 \dagger$ & $1.0 \pm 0.2$ \\
\hline
\end{tabular}

*Different from control at respective age, $p \leq 0.038$.

$\dagger$ Different from birth for respective diet, $p \leq 0.038$; all $p$ values adjusted for multiple comparisons.

$\ddagger$ Data in this column from Ref. 5 . 


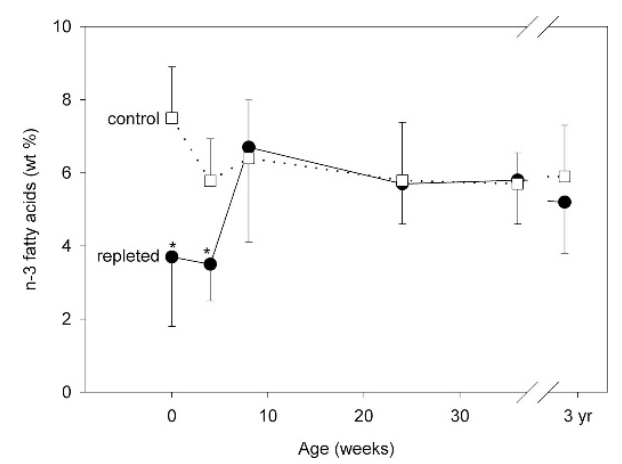

Figure 1. Repletion of $n-3$ fatty acids (mean \pm SD) in erythrocytes of prenatally n-3 fatty acid-deficient monkeys fed a control diet for $3 \mathrm{y}$ after birth. (Sample size for concurrent controls: $n=3-9$; sample size for repleted monkeys: $n=3-5$; see "Methods") Values at birth and termination are from Table 3. *Different from age-matched control at $p=0.042$ ( $t$ test, adjusted for multiple comparisons).

after birth in the control monkeys reflects the developmental pattern generally observed in both human and monkey infants fed soybean oil-containing infant formulas (5) in contrast to breast-fed infants who maintain their DHA levels after birth.

Fatty acid composition of cerebral cortex and retina. In newborn $\mathrm{n}$-3-deficient monkeys, the phospholipids of the prefrontal cerebral cortex and retina, normally highly enriched in DHA, had substantially reduced levels of DHA and other long-chain n-3 fatty acids. Table 4 illustrates values for PE and PS in prefrontal cortex, and Table 5 provides values for PE in the neural retina. In both tissues, the n-6 fatty acid 22:5(n-6) partially substituted for DHA.

After birth, recovery from n-3 fatty acid deficiency in the cerebral cortex was relatively rapid. Serial brain biopsies revealed that DHA levels in cortex PE had returned to control levels by $15 \mathrm{wk}$, the earliest time point sampled (Fig. $2 \mathrm{~A}$ ). In contrast, levels of 22:5(n-6) in cortex PE did not return to control values until $30-45 \mathrm{wk}$ of age (Fig. $2 B$ ). The levels of DHA continued to increase gradually from $15 \mathrm{wk}$ to $3 \mathrm{y}$, following the usual developmental pattern. After consuming the control diet for $3 \mathrm{y}$, these monkeys showed the same fatty acid profile as controls in both the PE and PS of the cerebral cortex. However, in the retinal PE, DHA remained $16 \%$ lower than in controls, total n-3 fatty acids were $14 \%$ lower, and 22:5(n-6) remained slightly elevated (Table 5). Thus, although recovery in retinal PE was substantial, it remained incomplete.

Because repletion in both the erythrocytes and cerebral cortex was already complete by the time of the earliest cortex biopsy, we cannot compare the relative kinetics of repletion in these two tissues. However, we can calculate that the maximum possible time lag between repletion in the erythrocytes and repletion in the brain was $7 \mathrm{wk}$, i.e. $15 \mathrm{wk}$ (age at the first biopsy, which showed full repletion in cortex) minus $8 \mathrm{wk}$ (time of full repletion in erythrocytes). Similarly, for 22:5(n-6), the maximum time-lag was $22-37 \mathrm{wk}$, the difference between $8 \mathrm{wk}$ and $30-45 \mathrm{wk}$, when this fatty acid reached normal levels in the cortex.

Visual acuity. Visual acuity thresholds did not differ significantly over time between control monkey infants and those exposed to prenatal n-3 fatty acid deficiency but subsequently repleted (Fig. 3). However, the small number of subjects did not provide sufficient power to detect a small difference. For comparison, previously published data from infants with combined prenatal and postnatal deficiency (6) are also shown in Figure 3; these infants had lower thresholds (i.e. poorer acuity) overall than either the control or repleted monkeys $(p=0.033$, between-diets posthoc test after two-way ANOVA, adjusted for multiple comparisons).

$\boldsymbol{E R G}$. In contrast to the visual acuity results, some small differences were found in the ERG at 3-4 mo of age. For cone system responses, flashes on an adapting background evoked significantly smaller a-wave amplitudes in the repleted group than in the control group (Fig. 4A) $(p=0.022)$; posthoc analyses found significant differences $(p<0.02)$ at two of the four intensities. A-wave peak latencies (Fig. $4 B$ ) were also shorter in the repleted group (overall $p=0.025 ; p<0.02$ at each of the three highest intensities). No differences were

Table 3. Fatty acid composition of erythrocytes from prenatally $n-3$ deficient monkeys at birth and after $2-3$ y of repletion with a control diet (percentage of total fatty acids, mean $\pm \mathrm{SD}$ )

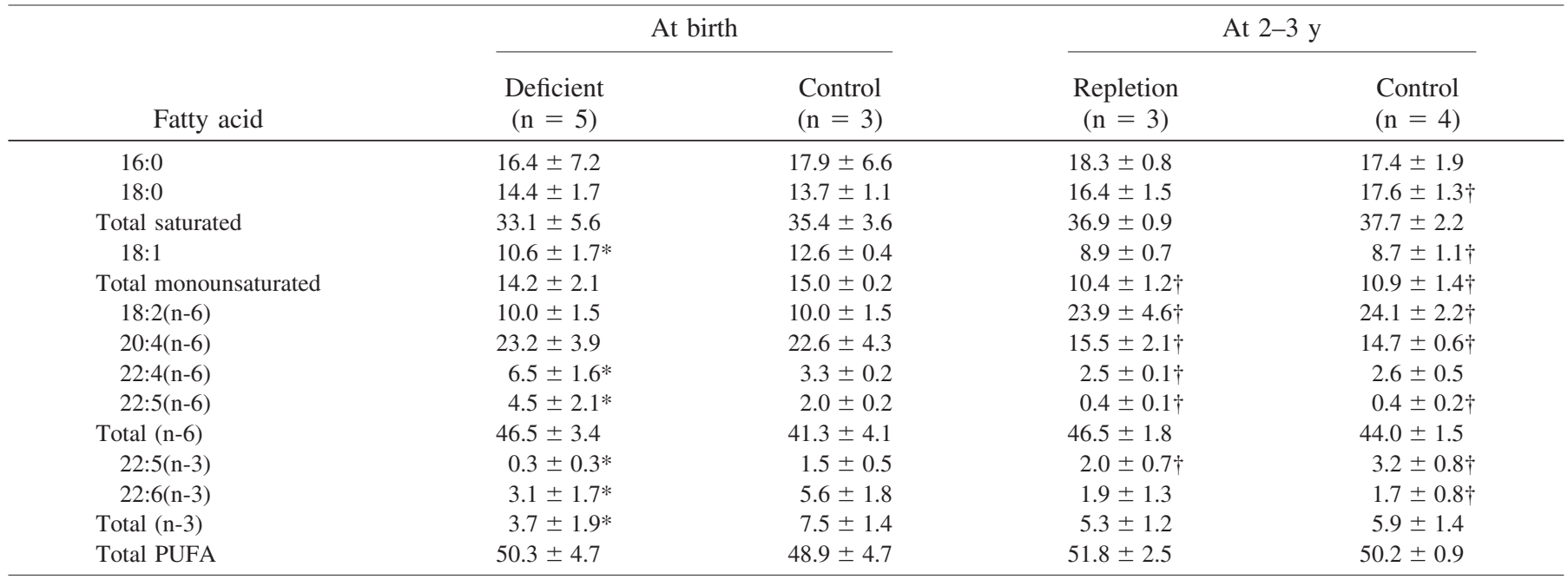

* Different from control at respective age, $p<0.047$.

$\dagger$ Different from birth for respective diet, $p<0.047$; all $p$ values adjusted for multiple comparisons. 
Table 4. The fatty acid composition of the phospholipid classes from frontal cortex of prenatally n-3 deficient monkeys at birth and after $2-3$ y of repletion with a control diet (percentage of total fatty acids, mean $\pm \mathrm{SD}$ )

\begin{tabular}{|c|c|c|c|c|c|c|c|c|}
\hline \multirow[b]{2}{*}{ Fatty acid } & \multicolumn{4}{|c|}{ PE } & \multicolumn{4}{|c|}{ PS } \\
\hline & $\begin{array}{c}\text { Deficient }+ \\
(\mathrm{n}=4)\end{array}$ & $\begin{array}{c}\text { Control } \neq \\
(\mathrm{n}=5)\end{array}$ & $\begin{array}{l}\text { Repletion } \\
(\mathrm{n}=3)\end{array}$ & $\begin{array}{c}\text { Control } \neq \\
(n=4)\end{array}$ & $\begin{array}{c}\text { Deficient } \\
(\mathrm{n}=4)\end{array}$ & $\begin{array}{l}\text { Control } \neq \\
(\mathrm{n}=5)\end{array}$ & $\begin{array}{l}\text { Repletion } \\
(\mathrm{n}=3)\end{array}$ & $\begin{array}{l}\text { Control } \$ \\
(\mathrm{n}=4)\end{array}$ \\
\hline $16: 0$ & $8.5 \pm 3.8$ & $4.8 \pm 1.9$ & $7.3 \pm 2.2$ & $6.4 \pm 1.9$ & $4.0 \pm 2.8$ & $3.5 \pm 1.8$ & $4.4 \pm 1.8$ & $2.7 \pm 1.9$ \\
\hline 18:0 & $26.6 \pm 2.9$ & $24.1 \pm 3.2$ & $26.4 \pm 7.2$ & $30.4 \pm 1.7$ & $41.1 \pm 2.4$ & $37.7 \pm 4.4$ & $38.3 \pm 3.5$ & $37.9 \pm 3.8$ \\
\hline Total monounsaturated & $13.8 \pm 4.6$ & $12.2 \pm 2.9$ & $6.7 \pm 0.8 \dagger$ & $9.5 \pm 1.5$ & $10.8 \pm 4.5$ & $9.7 \pm 1.8$ & $10.7 \pm 3.0$ & $6.4 \pm 0.9$ \\
\hline $18: 2(n-6)$ & $0.6 \pm 0.4$ & $0.5 \pm 0.2$ & $0.6 \pm 0.5$ & $0.9 \pm 0.4$ & $0.4 \pm 0.1$ & $0.5 \pm 0.2$ & $0.5 \pm 0.7$ & $1.4 \pm 1.8$ \\
\hline $20: 4(n-6)$ & $15.7 \pm 1.5$ & $17.9 \pm 2.1$ & $14.3 \pm 2.2$ & $12.8 \pm 1.0 \dagger$ & $5.6 \pm 1.1$ & $8.1 \pm 2.9$ & $2.9 \pm 0.6$ & $2.8 \pm 1.0 \dagger$ \\
\hline $22: 4(n-6)$ & $10.1 \pm 2.4$ & $11.8 \pm 1.7$ & $8.1 \pm 1.0$ & $8.8 \pm 2.1$ & $9.6 \pm 2.1$ & $9.6 \pm 1.5$ & $6.3 \pm 1.2 \dagger$ & $7.6 \pm 0.6$ \\
\hline $22: 5(n-6)$ & $10.8 \pm 3.6^{*}$ & $4.0 \pm 1.2$ & $1.5 \pm 1.4 \dagger$ & $1.4 \pm 0.2 \dagger$ & $16.8 \pm 5.4^{*}$ & $6.2 \pm 1.7$ & $1.5 \pm 1.2 \dagger$ & $2.9 \pm 0.4 \dagger$ \\
\hline Total (n-6) & $38.9 \pm 6.6$ & $35.8 \pm 4.3$ & $26.2 \pm 5.1 \dagger$ & $25.1 \pm 2.1 \dagger$ & $34.6 \pm 8.1$ & $26.7 \pm 4.4$ & $14.1 \pm 2.8 \dagger$ & $15.7 \pm 0.9 \dagger$ \\
\hline
\end{tabular}

All $p$ values adjusted for multiple comparisons.

PE: *Different from control at respective age, $p<0.012 ; \dagger$ different from birth for respective diet, $p<0.012$.

PS: *Different from control at respective age, $p<0.041 ; \dagger$ different from birth for respective diet, $p<0.041$.

$\ddagger$ Comparison data in these columns from Ref. 6 .

Table 5. Fatty acid composition of PE from the retina of prenatally n-3 deficient monkeys at birth and after 2-3 y of repletion with a control diet (percentage of total fatty acids, mean \pm SD)

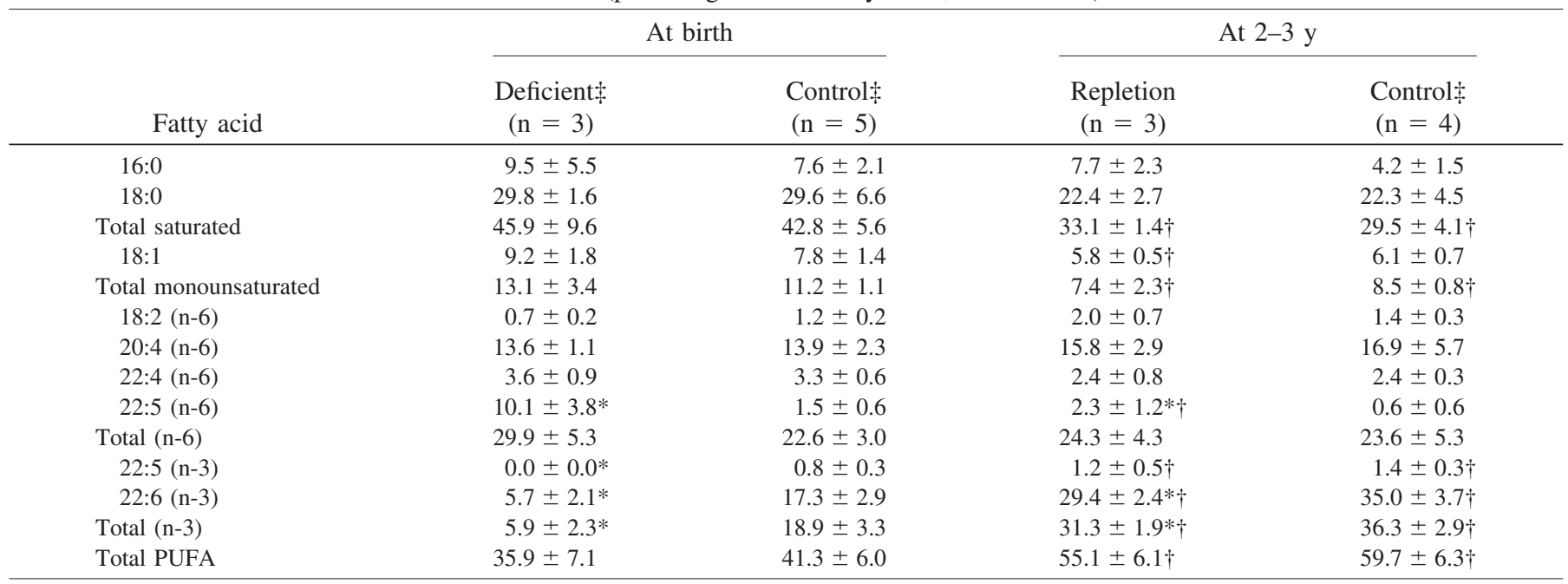

* Different from control at respective age, $p \leq 0.041$.

$\dagger$ Different from birth for respective diet, $p \leq 0.041$; all $p$ values adjusted for multiple comparisons.

\$ Comparison data in these columns from Ref. 6.

found in b-wave amplitudes or peak latencies, nor in any parameters of the ERG responses to flicker. For the darkadapted, rod system responses, there was a trend $(p=0.054)$ toward smaller a-wave amplitudes in the repleted group (Fig. 5). B-wave amplitudes and a-wave and b-wave peak latencies did not differ between the groups. Postflash recovery of both the a-wave and b-wave also showed no group differences (Fig. $6, A$ and $B$ ). In comparison, highly significant differences in cone and rod a-wave amplitudes and in the speed of a-wave and $b$-wave recovery previously were found in 3- to 4-mo-old infants deficient in $\mathrm{n}-3$ fatty acids both pre- and postnatally $(6,21)$.

\section{DISCUSSION}

$\mathrm{N}-3$ fatty acids have an important physiologic role in cell membranes of neural tissue (22-24). The significant role of these fatty acids is supported both by indirect observations such as the high enrichment and selective retention of n-3 fatty acids in the brain and retina, and by direct experimental evidence showing behavioral and physiologic abnormalities in n-3 fatty acid deficient animals $(4-6,25)$. Furthermore, several studies of formula-fed human term or preterm infants have demonstrated improved visual acuity or ERG parameters with 

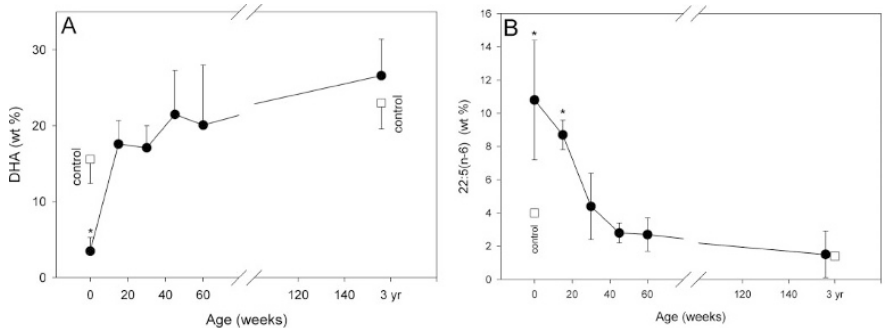

Figure 2. (A) Repletion of DHA (mean $\pm \mathrm{SD}$ ) in prefrontal cerebral cortex PE of prenatally n-3 fatty acid deficient monkeys fed a control diet for 3 y after birth. Data at 15-60 wk are from cortex biopsies of repleted monkeys only; data at birth and at termination are from Table 4. $* p<0.001 v s 0$ wk control ( $t$ test, adjusted for multiple comparisons). (B) Disappearance of 22:5(n-6) (mean $\pm \mathrm{SD}$ ) in prefrontal cerebral cortex PE of prenatally n-3 fatty acid deficient monkeys fed a control diet for 3 y after birth. Data at 15-60 wk are from cortex biopsies of repleted monkeys only; data at birth and at termination are from Table 4. ${ }^{*} p=0.02$ vs 0 wk control ( $t$ test, adjusted for multiple comparisons).

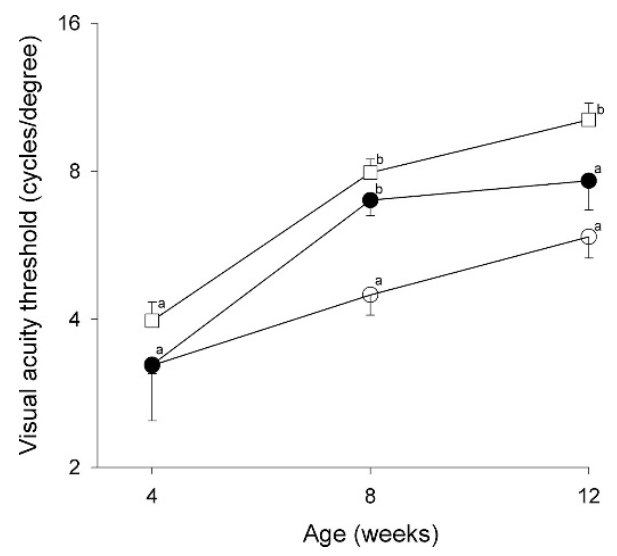

Figure 3. Visual acuity thresholds (mean \pm SE) at 4, 8, and 12 wk of age in control infants $(n=12)$ and those that were prenatally deficient in $n-3$ fatty acids but then repleted starting at birth $(n=4)$. The values in cycles per degree of visual angle indicate the smallest stripe size that elicited a behavioral response on at least $75 \%$ of presentations. Shown for comparison are acuity thresholds for deficient infants with combined prenatal and postnatal deficiency ( $n=10$, data from Ref. 6). Acuity in this deficient group was worse overall than in the control or repleted groups $(p=0.033$, between-diets posthoc test after two-way ANOVA, adjusted for multiple comparisons). Individual data points carrying different superscripts at a given time point are different at $p \leq 0.023$. $\square-$ Control; $\bigcirc-$ Deficient; $\square-$ Repleted.

higher dietary supply of alpha-linolenic acid or with the addition of preformed dietary DHA [reviewed in $(8,26)$ ].

We previously reported many biochemical and physiologic alterations in rhesus monkeys with $\mathrm{n}-3$ fatty acid deficiency induced by a combination of maternal and postnatal diets low in alpha-linolenic acid. These alterations included impaired visual acuity development, electroretinographic changes, increased fluid consumption, and the presence of abnormal phospholipid molecular species in the brain and retina $(5,6,10-$ 12,27). A critical question regarding the long-term effects of n-3 fatty acid deficiency during development is the degree to which these effects are reversible. Rhesus monkeys with combined prenatal and postnatal n-3 fatty acid deficiency through 10-24 mo of age failed to recover fully with respect to the most sensitive ERG parameters, including delayed b-wave implicit times (peak latencies) and recovery functions, even after subsequent repletion with a DHA-rich diet for $36 \mathrm{wk}$
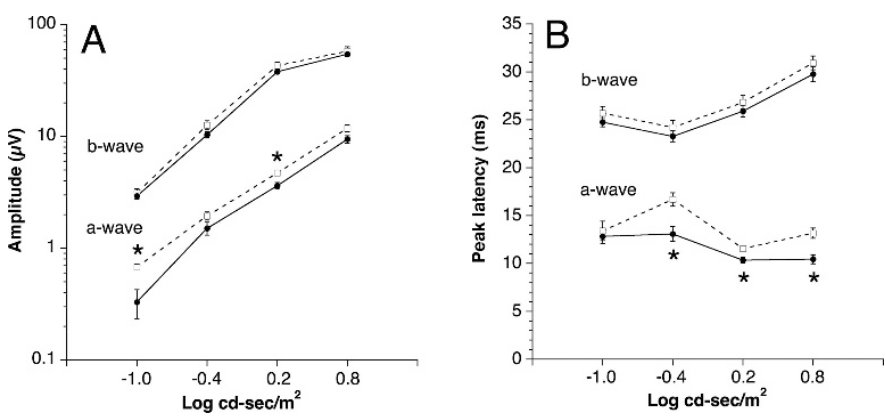

Figure 4. (A) Amplitudes of the a-wave and b-wave of the cone-dominated ERG (mean \pm SE) at 3-4 mo of age in control infants $(n=5)$ and those that were prenatally deficient in n-3 fatty acids but then repleted starting at birth ( $n$ $=4)$. A-wave amplitudes were smaller in the repleted group $(p=0.022$ overall by ANOVA). *Intensities with $p<0.02$ in post hoc analyses. (B) Peak latencies (implicit times) of the a-wave and b-wave of the cone-dominated ERG (mean \pm SE) at 3-4 mo of age in control infants $(n=5)$ and those that were prenatally deficient in $n-3$ fatty acids but then repleted starting at birth ( $n$ $=4)$. A-wave latencies were shorter in the repleted group ( $p=0.025$ overall by ANOVA). * indicates intensities with $p<0.02$ in post hoc analyses. -- $\square--$ Control; $\rightarrow-$ Repleted.

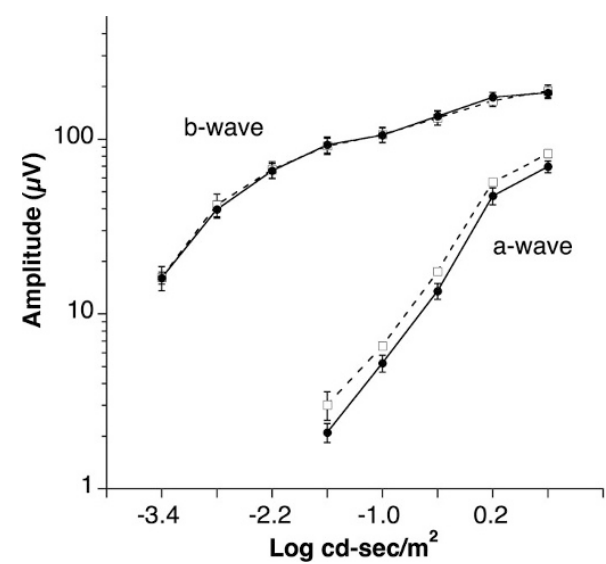

Figure 5. Amplitudes of the a-wave and b-wave of the rod-dominated ERG (mean \pm SE) at 3-4 mo of age in control infants $(n=5)$ and those that were prenatally deficient in n-3 fatty acids but then repleted starting at birth $(n=4)$. A-wave amplitudes showed a borderline decrease in the repleted group ( $p=$ 0.054 overall by ANOVA). --口-- Control; $\multimap-$ Repleted.
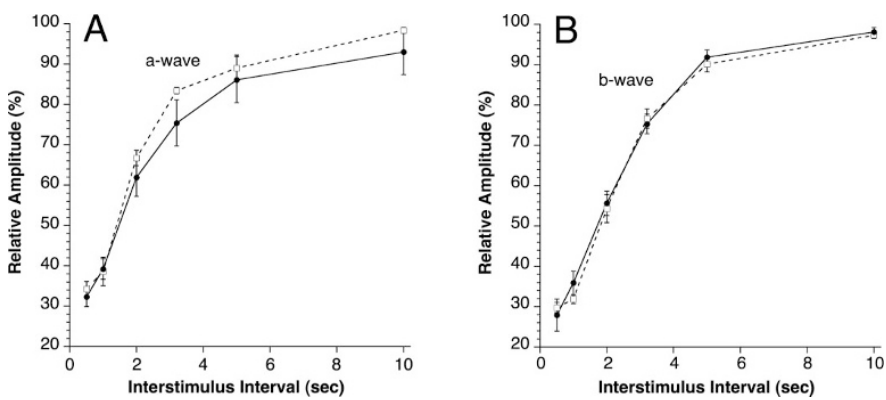

Figure 6. Recovery of the a-wave $(A)$ and b-wave $(B)$ of the rod-dominated ERG (mean \pm SE) at 3-4 mo of age in control infants $(n=5)$ and those that were prenatally deficient in n-3 fatty acids but then repleted starting at birth $(n$ $=4)$. Speed of recovery did not differ between the groups. -- $\square-$ - Control; $\longrightarrow-$ Repleted.

$(14,21)$. Brain fatty acid composition, measured with frontal cortex biopsies, had completely normalized by 12 wk of repletion, and retinal DHA was normal at the time of termination at $>40$ wk. These findings suggested that n-3 fatty acid defi- 
ciency at a critical stage in primate development may cause lasting functional alterations.

In the current work, we attempted to define further the window of vulnerability by beginning dietary reversal at birth of a deficiency induced in utero. At birth there was a marked biochemical $n-3$ fatty acid deficiency in blood and tissues, but $\mathrm{n}-3$ fatty acid levels rose to control values in plasma by $4 \mathrm{wk}$ of age, in erythrocytes by $8 \mathrm{wk}$, and in cerebral cortex within 15 wk after birth. In addition, the compensatory elevation in n-6 fatty acids, particularly 22:5(n-6), which partially replaced DHA, had dissipated by approximately the same time point in plasma but slightly more slowly in erythrocytes (by $12 \mathrm{wk}$ ) and in the cerebral cortex (by 30-45 wk). However, in the retina there was a failure of the repletion diet to completely reverse the biochemical effects of the intrauterine $n-3$ fatty acid deficiency, such that both DHA and 22:5(n-6) levels incompletely recovered to control levels even after three years of the highalpha-linolenic acid repletion diet. With regard to functional effects of prenatal deficiency, no differences were detected in visual acuity development in the early postnatal months, but at 3-4 mo, ERG a-waves, which largely reflect photoreceptor activity, were significantly reduced for the cone system, and there was a similar but borderline effect for the rod system. Previous studies of combined prenatal and postnatal n-3 fatty acid deficiency at this age found significant differences in these ERG measures (21) as well as effects on other ERG parameters, including postflash recovery. However, it must be noted that the number of prenatally deficient subjects provided limited power to detect small differences.

A study by Birch et al. (28) found a similar reduction in rod a-wave amplitudes of preterm, very-low-birthweight human infants fed a low-alpha-linolenic acid corn oil-based infant formula. This study also found differences in rod b-wave amplitude, threshold and sensitivity. The ERG changes were present at $36 \mathrm{wk}$ gestational age (near term) but were no longer present at $57 \mathrm{wk}$ gestational age (4 mo post term). The period of limited n-3 fatty acid supply in these infants, equivalent to the third trimester of full-term gestation, corresponds approximately to mid- to late gestation in the rhesus monkey when our monkeys received an inadequate supply of $\mathrm{n}-3$ fatty acids in utero. Malcolm et al. (29) found no significant effect of fish oil supplementation of pregnant mothers on the newborn infant ERG; however, infant cord blood DHA was correlated with sensitivity, but not amplitude, of the ERG b-wave.

It is of interest that the recovery of brain DHA appeared to be slower in these monkeys fed a repletion diet containing alpha-linolenic acid than in our earlier study, cited above, where n-3 fatty acid deficient monkeys were repleted with a diet containing high levels of fish oil rich in DHA (14). The earlier study involved repletion later in life, at 10-24 mo of age, so the two are not strictly comparable. Nevertheless, in the earlier study monkey cerebral cortex DHA levels rose to control values within 12 wk. Similarly, in the present study, erythrocytes still had not responded to the repletion diet at 4 wk, whereas fish oil produced substantial increases in erythrocyte DHA after 2 wk (14). We previously also observed the superiority of dietary DHA over its 18-carbon dietary precursor, alpha-linolenic acid, in repletion studies in chicks (30).
The synthesis of DHA from alpha-linolenic acid occurs slowly, and the feeding of alpha-linolenic acid in humans does not produce an appreciable increase in plasma or breast milk DHA (31-33). Dietary alpha-linolenic acid was ultimately effective at reversing most of the biochemical deficiency in rhesus monkeys in the current long-term study. However, the present study does not directly address the question of whether preformed DHA in the repletion diet would have produced more rapid or complete reversal of the deficiency.

The picture in other animal models is variable, due to differences in methodology as well as species. For instance, Weisinger et al. (34) observed a complete return to normal of the ERG in guinea pigs fed an n-3 fatty acid-deficient diet after weaning followed by a 10-wk repletion period with a highalpha-linolenic acid diet. ERG recovery occurred despite the fact that retinal DHA did not completely rise to control values and 22:5(n-6) did not decay completely to control levels within this time. These results agree with our biochemical findings but stand in contrast to our earlier work in monkeys discussed above (21), where the ERG effects of n-3 fatty acid deficiency were irreversible despite full recovery of tissue n-3 fatty acid levels after repletion with fish oil. However, the same investigators (35) found that perinatal n-3 fatty acid deficiency led to a significant increase in adult blood pressure despite repletion of young n-3 fatty acid deficient rats with a high-alpha linolenic acid diet from 9 wk of age onward.

Bourre et al. (36) found that brain levels of DHA were slow to reach normal levels when prenatally $n-3$ fatty acid deficient rats were switched to a repletion diet at $60 \mathrm{~d}$ of age. Ten weeks later, brain DHA had increased to only approximately $75 \%$ of control, although brain 22:5(n-6) decayed completely to control values within this time period. In contrast, the retina showed an opposite pattern, with 22:5(n-6) recovering more slowly than DHA, as in the current work with monkeys. However, the rat retina did eventually achieve control values for both DHA and 22:5(n-6). More recently, this group demonstrated incomplete reversal of abnormal behavior patterns in n-3 fatty acid deficient mice, correlating with incomplete recovery of DHA in the frontal cortex (37). On the other hand, Moriguchi et al. (38) reported rapid repletion of rat brain DHA levels after only 8 wk using a DHA-supplemented diet, and Ikemoto et al. (39) noted a complete reversal of learning deficits when n-3 fatty acid deficient weanlings were repleted.

Rats and other small animals have limitations as models for human nutritional deficiencies. Nonhuman primates can provide a closer approximation to human metabolism and nutritional requirements, the timing of developmental processes, and critical anatomy. Not only is the primate brain highly developed, but the primate retina shares many unique characteristics with the human, including a central retina rich in cone photoreceptors and a specialized fovea responsible for high visual acuity.

Inasmuch as postnatal repletion of n-3 fatty acid deficient monkeys with a high alpha-linolenic acid diet apparently did not fully reverse the fatty acid compositional abnormalities seen in the retina at birth, it would seem prudent to suggest that pregnant human females not consume a diet deficient in $\mathrm{n}-3$ fatty acids. Although a diet containing a variety of plant and 
animal products would avoid potential n-3 fatty acid deficiency, certain human populations could inadvertently consume a diet with a high (n-6)/(n-3) ratio. For instance, by eliminating most animal products from the diet and deriving fat only from certain vegetable oils, such as corn, sunflower, safflower, or peanut oils, that have a very low proportion of alpha-linolenic acid and a high proportion of linoleic acid, the expectant mother could consume a diet similar to that of the rhesus monkeys who gave birth to n-3 fatty acid deficient infants in this study.

In summary, n-3 fatty acid deficiency limited to the prenatal period appeared to have no lasting effects on the fatty acid composition of most tissues in rhesus monkeys after three postnatal years on a control diet adequate in n-3 fatty acids. The possible important exception was the retina, where recovery from the initial deficiency was substantial but incomplete, both biochemically and functionally. Because of the observation of irreversible visual deficits in an earlier repletion study in rhesus monkeys (21), and the documented effects on visual and mental development of dietary n-3 fatty acids in human infants $(9,28,40,41)$ we suggest that it is prudent to ensure an adequate intake of $n-3$ fatty acids during pregnancy as well as for the infant after birth.

Acknowledgments. The authors thank Sydney Reisbick, Kim Saunders, and Noelle Landauer for participation in acuity and ERG data collection and analysis, and Louise Barstad for technical assistance with biochemical measurements

\section{REFERENCES}

1. Fliesler SJ, Anderson RE 1983 Chemistry and metabolism of lipids in the vertebrate retina. Prog Lipid Res 22:79-131

2. Pawlosky RJ, Denkins Y, Ward G, Salem N Jr 1997 Retinal and brain accretion of long-chain polyunsaturated fatty acids in developing felines: The effects of corn oilbased maternal diets. Am J Clin Nutr 65:465-472

3. Neuringer M, Anderson GJ, Connor WE 1988 The essentiality of n-3 fatty acids for the development and function of the retina and brain. Annu Rev Nutr 8:517-541

4. Benolken RM, Anderson RE, Wheeler TG 1973 Membrane fatty acids associated with the electrical response in visual excitation. Science 182:1253-1254

5. Neuringer M, Connor WE, Van Petten C, Barstad L 1984 Dietary omega-3 fatty acid deficiency and visual loss in infant rhesus monkeys. J Clin Invest 73:272-276

6. Neuringer M, Connor WE, Lin DS, Barstad L, Luck S 1986 Biochemical and functional effects of prenatal and postnatal omega 3 fatty acid deficiency on retina and brain in rhesus monkeys. Proc Natl Acad Sci U S A 83:4021-4025

7. Neuringer M 2000 Infant vision and retinal function in studies of dietary long-chain polyunsaturated fatty acids: methods, results, and implications. Am J Clin Nutr 71:256S-267S

8. SanGiovanni JP, ParraCabrera S, Colditz GA, Berkey CS, Dwyer JT 2000 Metaanalysis of dietary essential fatty acids and long- chain polyunsaturated fatty acids as they relate to visual resolution acuity in healthy preterm infants. Pediatrics 105:12921298

9. O'Connor DL, Hall R, Adamkin D, Auestad N, Castillo M, Connor WE, Connor SL, Fitzgerald K, Groh-Wargo S, Hartmann EE, Jacobs J, Janowsky J, Lucas A, Margeson D, Mena P, Neuringer M, Nesin M, Singer L, Stephenson T, Szabo J, Zemon V; Ross Preterm Lipid Study 2001 Growth and development in preterm infants fed long-chain polyunsaturated fatty acids: a prospective, randomized controlled trial. Pediatrics 108:359-371

10. Reisbick S, Neuringer M, Hasnain R, Connor WE 1990 Polydipsia in rhesus monkeys deficient in omega-3 fatty acids. Physiol Behav 47:315-323

11. Lin DS, Connor WE, Anderson GJ, Neuringer M 1990 Effects of dietary n-3 fatty acids on the phospholipid molecular species of monkey brain. J Neurochem 55:12001207
12. Lin DS, Anderson GJ, Connor WE, Neuringer M 1994 Effect of dietary n-3 fatty acids upon the phospholipid molecular species of the monkey retina. Invest Ophthalmol Vis Sci 35:794-803

13. Teller DY, Morse R, Borton R, Regal D 1974 Visual acuity for vertical and diagonal gratings in human infants. Vision Res 13:1433-1439

14. Connor WE, Neuringer M, Lin DS 1990 Dietary effects on brain fatty acid composition: the reversibility of n-3 fatty acid deficiency and turnover of docosahexaenoic acid in the brain, erythrocytes, and plasma of rhesus monkeys. J Lipid Res 31:237247

15. Bligh EG, Dyer WJ 1959 A rapid method of total lipid extraction and purification. Can J Biochem Physiol 37:911-917

16. Rose HG, Oklander M 1965 Improved procedure for the extraction of lipids from human erythrocytes. J Lipid Res 6:428-431

17. Folch J, Lees M, Sloane-Stanley GH 1957 A simple method for the isolation and purification of total lipids from animal tissues. J Biol Chem 226:497-509

18. Morrison WR, Smith LM 1964 Preparation of fatty acid methyl esters and dimethylacetals from lipids with boron fluoride-methanol. J Lipid Res 5:600-608

19. Winer BJ 1971 Statistical Principles in Experimental Design. McGraw-Hill, New York, pp 445-449

20. Miller RG 1966 Simultaneous Statistical Inference. McGraw-Hill, New York, pp 5-11

21. Neuringer M, Connor WE, Lin DS, Anderson GJ, Barstad L 1991 Dietary omega-3 fatty acids: effects on retinal lipid composition and function in primates. In: Anderson RE, Hollyfield JG, LaVail MM (eds) Retinal Degenerations. CRC Press, New York, pp 117-129

22. Fernstrom JD 1999 Effects of dietary polyunsaturated fatty acids on neuronal function. Lipids 34:161-169

23. Jeffrey BG, Weisinger HS, Neuringer M, Mitchell DC 2001 The role of docosahexaenoic acid in retinal function. Lipids 36:859-871

24. Niu SL, Mitchell DC, Lim SY, Wen ZM, Kim HY, Salem N Jr, Litman BJ 2004 Reduced $\mathrm{G}$ protein-coupled signaling efficiency in retinal rod outer segments in response to n-3 fatty acid deficiency. J Biol Chem 279:31098-31104

25. Innis SM 2000 Essential fatty acids in infant nutrition: lessons and limitations from animal studies in relation to studies on infant fatty acid requirements. Am J Clin Nutr 71:238S-244S

26. Uauy R, Hoffman DR, Mena P, Llanos A, Birch EE 2003 Term infant studies of DHA and ARA supplementation on neurodevelopment: results of randomized controlled trials. J Pediatr 143:S17-S25

27. Jeffrey BG, Mitchell DC, Gibson RA, Neuringer M 2002 n-3 fatty acid deficiency alters recovery of the rod photoresponse in rhesus monkeys. Invest Ophthalmol Vis Sci 43:2806-2814

28. Birch DG, Birch EE, Hoffman DR, Uauy RD 1992 Retinal development in very-lowbirth-weight infants fed diets differing in omega-3 fatty acids. Invest Ophthalmol Vis Sci 33:2365-2376

29. Malcolm CA, Hamilton R, McCulloch DL, Montgomery C, Weaver LT 2003 Scotopic electroretinogram in term infants born of mothers supplemented with docosahexaenoic acid during pregnancy. Invest Ophthalmol Vis Sci 44:3685-3691

30. Anderson GJ, Connor WE, Corliss JD 1990 Docosahexaenoic acid is the preferred dietary n-3 fatty acid for the development of the brain and retina. Pediatr Res 27:89-97

31. Sanders TA, Younger KM 1981 The effect of dietary supplements of omega 3 polyunsaturated fatty acids on the fatty acid composition of platelets and plasma choline phosphoglycerides. Br J Nutr 45:613-616

32. Pawlosky RJ, Hibbeln JR, Novotny JA, Salem N Jr 2001 Physiological compartmental analysis of alpha-linolenic acid metabolism in adult humans. J Lipid Res 42:1257-1265

33. Francois CA, Connor SL, Wander RC, Connor WE 1998 Acute effects of dietary fatty acids on the fatty acids of human milk. Am J Clin Nutr 67:301-308

34. Weisinger HS, Vingrys AJ, Bui BV, Sinclair AJ 1999 Effects of dietary n-3 fatty acid deficiency and repletion in the guinea pig retina. Invest Ophthalmol Vis Sci 40:327338

35. Armitage JA, Pearce AD, Sinclair AJ, Vingrys AJ, Weisinger RS, Weisinger HS 2003 Increased blood pressure later in life may be associated with perinatal n-3 fatty acid deficiency. Lipids 38:459-464

36. Bourre JM, Durand G, Pascal G, Youyou A 1989 Brain cell and tissue recovery in rats made deficient in n-3 fatty acids by alteration of dietary fat. $J$ Nutr 119:15-22

37. Carrie I, Clement M, de Javel D, Frances H, Bourre JM 2000 Phospholipid supplementation reverses behavioral and biochemical alterations induced by $n-3$ polyunsaturated fatty acid deficiency in mice. J Lipid Res 41:473-480

38. Moriguchi T, Loewke J, Garrison M, Catalan JN, Salem N Jr 2001 Reversal of docosahexaenoic acid deficiency in the rat brain, retina, liver, and serum. J Lipid Res 42:419-427

39. Ikemoto A, Ohishi M, Sato Y, Hata N, Misawa Y, Fujii Y, Okuyama H 2001 Reversibility of n-3 fatty acid deficiency-induced alterations of learning behavior in the rat: level of n-6 fatty acids as another critical factor. J Lipid Res 42:1655-1663

40. Birch EE, Hoffman DR, Uauy R, Birch DG, Prestidge C 1998 Visual acuity and the essentiality of docosahexaenoic acid and arachidonic acid in the diet of term infants. Pediatr Res 44:201-209

41. Birch EE, Garfield S, Hoffman DR, Uauy R, Birch DG 2000 A randomized controlled trial of early dietary supply of long-chain polyunsaturated fatty acids and mental development in term infants. Dev Med Child Neurol 42:174-181 